\title{
Understanding Governmental Spending on Public Cultural Services: Exploring the Effects of Fiscal Decentralization Variables
}

\author{
Bin $\mathrm{Tu}^{*}$, Xiangyu Tao², Nian'en Guo ${ }^{2}$ \\ ${ }^{1}$ Guangdong Research Center for NPO, Guangdong University of Foreign Studies, Guangzhou, China \\ ${ }^{2}$ School of Politics and Public Administration, Guangdong University of Foreign Studies, Guangzhou, China \\ Email: *hattytu@126.com
}

How to cite this paper: Tu, B., Tao, X.Y. and Guo, N.E. (2017) Understanding Governmental Spending on Public Cultural Services: Exploring the Effects of Fiscal Decentralization Variables. Theoretical Economics Letters, 7, 709-727.

https://doi.org/10.4236/tel.2017.74051

Received: April 17, 2017

Accepted: May 14, 2017

Published: May 17, 2017

Copyright $\odot 2017$ by authors and Scientific Research Publishing Inc. This work is licensed under the Creative Commons Attribution International License (CC BY 4.0).

http://creativecommons.org/licenses/by/4.0/

\begin{abstract}
This article explores the fiscal decentralization factors that affect government spending on public culture services in two main points-imbalance in revenue power and spending responsibility and promotion tournament by using provincial panel data from 1997 to 2015 in China. The results yield three noteworthy findings. First, fiscal decentralization in spending responsibility significantly reduced the proportion of government spending on public cultural services to government spending. The public financial self-sufficiency has a significant positive effect on the ratio of public cultural expenditure and public spending. Second, the coefficient of transfer payment is significantly negative, namely, the current transfer payment in China cannot increase the proportion of public cultural expenditure effectively. Third, the coefficient of government official promotion competition has also a significantly negative effect on public cultural spending. This research contributes to the literature in several ways, most notably by incorporating a more open-systems approach to the study of government spending on public culture services with the inclusion of several fiscal decentralization variables.
\end{abstract}

\section{Keywords}

Government Spending, Public Culture Services, Fiscal Decentralization, Promotion Tournament

\section{Introduction}

Public cultural facilities (such as library, museum, memorial, art museum and cultural center etc.), cultural products, cultural activities and other related cultural services are very important deliveries for government to meet the public's 
basic cultural needs. In China, these significant deliveries are referred to as public cultural services provided mainly by government due to the slow development of cultural nonprofit organizations. The essence of public cultural services is, in the citizen, to form identity on positive value orientation and noble spiritual pursuit which can shape people's good behavior, and maintain social stability. At present, the insufficient financial expenditure and lower efficiency on public cultural services have greatly affected the function of public cultural service. All of these functions are predicated on government spending sustainability and require a strong understanding of the factors that affect government expenditure on public cultural. This article contributes to that knowledge by exploring the determinants of government expenditure on public cultural services.

This line of inquiry began with Michael Getzner [1], who explored the factors affecting public cultural spending which were GDP, the ideology of ruling parties, the form of government and political business cycles. Subsequent studies [2] show that municipalities' cultural spending is generally positively affected by that in neighbouring municipalities. Electoral timing on municipal will affect public cultural spending, income and upper-level governments' transfers have a positive impact on cultural spending [3].

In China, research of government cultural spending is the focus on the view as followings: First, government spending on public cultural service is very important to the construction of public cultural service system, but the scale of government expenditure in public cultural service system is not enough; the overall efficiency of the use of financial funds is not high [4] [5] [6]. On one hand, cultural expenditure accounted for the proportion of the national financial expenditure is low, maintained at around $0.4 \%$ level, and hasn't increased for many years with keeping at a certain level. On the other hand, compared with education, health, science and technology business government spending, government cultural expenditure accounted for the proportion of the national fiscal expenditure was also low [7] [8]. Furthermore, two indicators, the ratio of government expenditure on public cultural services to total national fiscal expenditure and the proportion of infrastructure investment in public cultural services and national infrastructure investment from 2000 to 2005 were still low [9]. There was a large gap in the ratio government spending on public cultural service to national fiscal expenditure between China and the countries above medium degree of development, the ratio of those countries was almost over 1\% [10]. Second, explaining why government spending efficiency on public cultural service was lower than other public service area and other country with the similar economic develop level. The main reason opinion is that there are no clear quantitative indicators in a higher level of legal documents in government cultural spending, which can weakened legally binding of cultural expenditure in local governments at all levels. Thus, for government, it will lead to pay attention to economic construction and neglect of cultural construction, emphasis on education and health investment but contempt for cultural investment [11] [12]. Third, it's important for every level government with authoritative higher legal form to 
make sure growth rate of budget of public cultural services at all levels, the proportion between the central and local government cultural expenditure [7] [11] [13].

Despite this recognition, researchers in China predominantly describe the phenomenon in government cultural spending, and lack of in-depth analysis. The idea that government cultural spending was not enough has been discussed, but rarely mentions the effects of fiscal decentralization. What range of public cultural services different level government finance? Whether the revenues are commensurate with these responsibilities in government cultural spending at every level government? What factor will affect the government cultural spending structure? As a result, we do not have a clear understanding of the effects of fiscal decentralization.

Identifying fiscal decentralization factors and determining how they affect government cultural spending present a critical reference to the development on public culture, especially to the achievement of the government cultural functions to the great extent. There is a positive practical significance for effectively optimizing the allocation and utilization of public financial resources in the field of culture and maximizing the effectiveness of limited financial resources.

\section{Theoretical Framework and Hypothesis Analysis}

\subsection{Imbalance in Revenue Power and Spending Responsibility Affect Public Cultural Expenditure}

Power and responsibility are innate "twins" and inseparable unity, just like rights and obligations. Power must be accompanied by the responsibility. If the power was blindly limited, the corresponding duties and responsibility couldn't be performed better. The power and responsibility of delivery in public cultural services also need to be balanced in the local governments. But there is still an imbalance in revenues resource and spending responsibility which could affect public cultural expenditure in China.

Almost any country's government system is divided into several levels; through the distribution of power to achieve the coordinated development of regional economy is an important goal of the central government. Fiscal decentralization refers that the local government is given a certain amount of tax power and expenditure responsibilities, and it is allowed its own discretion to determine the size and structure of budget expenditures, so that local governments at the grass roots level can freely choose the type of policy they need and actively participate in social governance, the result is to enable local governments to provide more and better services. Fiscal decentralization covers two interrelated issues. The first is the division of spending responsibilities and revenue sources between levels of government (national, regional, local etc.). The second is the amount of discretion given to regional and local governments to determine their expenditures and revenues (both in aggregate and detail) [14]. In most countries local government is responsible for what are often called "public services". Public cultural service is one kind of the public services. Fiscal decentralization can im- 
prove the efficiency of public cultural service delivery through preference matching and allocative efficiency. The reality of the efficiency from fiscal decentralization needs a basic prerequisite, which is the allocation of intergovernmental public services expenditure should be the balance of expenditure and revenues resources. However, there is an imbalance between the expenditure responsibility of intergovernmental public cultural services and the allocation of public revenues resources in China. The imbalance have affected the government spending on public cultural services (public cultural spending) since fiscal decentralization in 1994.

\section{The Spending Responsibility Variable}

Public cultural expenditure in China is shared by the central and local governments, but mainly responsible by the local government for a long time. From 1985 to 2015, the local government's public cultural expenditure accounted for more than $90 \%$, and most of them are over than $92 \%$, several years are beyond 95\%, until 2015 data show that exceed 95\%, 21 years of local public cultural expenditure accounted for an average of $93.9 \%$ of the total expenditure. In other words, the responsibility of the public cultural service is mainly completed by the local government, although the fiscal decentralization reform in 1980, especially after the taxation system in 1994, the local government tax division pattern has changed, local government revenue accounted for the proportion of total revenue decline. The division of responsibility for public cultural expenditure still inherited the characteristics of the planned economy system, and did not change with the tax division model to make the corresponding changes. Local governments still have to bear the responsibility to provide the vast majority of basic public cultural services. It can be seen that the absolute growth of national public cultural expenditure mainly comes from the growth of local public cultural expenditure, and the change of public cultural expenditure of central government is not significant.

At the same time public cultural expenditure responsibility between provincial and other levels government below provincial governments have been dislocation. Other levels, government below provincial governments (municipal, county, and township) need to assume a huge responsibility for public cultural expenditure. More than $90 \%$ of public cultural spending is borne by the provinces and below, and $71 \%$ of the expenditure taking place at the municipal, county and township levels, especially at the county and township levels. Public cultural services belong to the public service with strong spillover; their expenses shouldn't bear by the county and township governments. In 2013, the county and township governments have paid nearly $50 \%$ of public cultural expenditure.

The dislocation of the responsibility of public cultural expenditure at all government levels is largely caused by the moving down of responsibility level by level for long-term expenditure. There are five levels in government level system in China, including the central, provincial (autonomous regions and municipalities), regional (prefecture-level cities, autonomous prefectures), county (county) and township (town). There is a lack of a clear and formal division in public ex- 
penditure. The Constitution has, in principle, stipulated the respective responsibility range of the central and local governments, but has not passed legislation to clarify the responsibilities of governments at all levels. Although the Budget Act guarantees local budget autonomy, it only divides expenditure between the central and local governments. The central government has no specific guidelines on the division of expenditure among governments below the provincial level, so that the division of the scope of the expenditure is too general.

The unclear division of responsibilities leads to the de facto localization of expenditure responsibilities. Many important public services have been arranged by local governments, although the fiscal system has undergone dramatic changes since 1980s, the division on important responsibilities remains similar to the division of responsibilities in the 1970s. From the beginning of the First Five period to the present, local government public cultural expenditure is more than $90 \%$ of total expenditure. In many countries, the proportion of public cultural expenditure in the proportion of public expenditure, the central and local is almost half of each. To identify if there is a relationship between allocation of the responsibility of the public spending and public cultural expenditure, it is hypothesized as follows:

Hypothesis 1 (H1): Allocation of the intergovernmental spending responsibility is positively associated with the government cultural spending.

\section{The Revenue Resource Variable}

Most of the responsibility for public cultural expenditure is assumed by local governments in China. It couldn't lead to the inefficiency of public cultural services if local governments at all levels have enough revenues resource. The revenue resource is normally composed of a combination of local taxes, user fees, inter-governmental transfers. Allocation of revenues like local taxes which were moved up level by level among level governments has become a clear trend after the taxation system reform since 1994. Every higher-level government is always as much as possible to occupy a greater proportion of fiscal revenue, and divide the responsibility of fiscal expenditure to lower levels government. Between the central government and the provincial government, to the utmost extent, after taxes division the revenues are concentrated in the central government which can increases the central fiscal revenue at the end. Among governments below provincial level, revenues except intergovernmental transfers are also moved to higher levels governments. That means lower level governments have less local taxes allocation than the higher level governments. This study will test the following hypothesis:

Hypothesis 2 (H2): The revenue resource except intergovernmental transfers is positively associated with the public cultural expenditure.

\section{Intergovernmental Transfers Variable}

Then how about intergovernmental transfers, the other main revenue resource? The delivery of public cultural service system is embedded in the government administrative system, with the two dimensions of departmental management and level management. The provision of public cultural services was 
mainly implemented by various cultural departments in all level governments, which get partly fund from the cultural budget in all level government. The other part fund is from the transfer of higher levels of government. The intergovernmental transfer mainly includes special project transfer, general transfer, tax returns, institutional subsidies, settlement subsidies and other transfer. But these transfer payments couldn't be enough to solve the local government in the public cultural expenditure. At present, culture special grant from central government to the local government is managed and shared by the Ministry of Finance and the central cultural authorities including the Ministry of Culture, the State Press and Publication Administration and the State Administration of Radio and Television. Special transfer payments for culture are mainly carried out in the form of special projects. Although the special project usually has strict approval procedures, but the project efficiency of public culture spending is still low due to unreasonable project approval, the lack of normative funding basis and standards, the lack of effective supervision on the using of funds. All these may have led to funds not using in the provisions of the project, the special transfer funds may be even misappropriated and retained by the local government. The general transfer of public expenditure is not specified in the use of the direction. So it is difficult to standardize the funds payment process. The funds could be squeezed for using as a productive expenditure in public services which, to a certain extent, reflect the government official's performance. The government official would rather prefer to expenditure on educate and health services than public culture. To identify if there is a relationship between intergovernmental transfers and public cultural expenditure, it is hypothesized as follows:

Hypothesis 3 (H3): Intergovernmental transfers are positively associated with public cultural expenditure.

Therefore, Public cultural spending responsibility was moved to lower levels government level by level, the responsibility overmuch focus on the government below provincial governments. At the same time, revenues control power are moved to higher levels governments level by level. Thus, the mismatch between responsibility and revenues control power in public cultural spending, leads to the lack of full delivery in public cultural service.

\subsection{Promotion Competition Affect Public Cultural Expenditure}

The proportion of local public cultural expenditure and the fiscal expenditure is a reflection of the behavior of local government. From the perspective of public economics, as an independent "rational person", the government action is dominated by government officials' preference. Government action changes with changes in government officials' preferences. When local governments prefer cultural development, local public cultural spending will increase. When local governments prefer other activities, then public cultural spending will be decrease.

Fiscal decentralization clearly stipulates that the local government has the autonomy of local expenditure. We can see that the financial decentralization of 
local officials have the right to disposal of economic resource.

Under the background of fiscal decentralization, incentives from performance assessment bring high-speed economic growth in China [15] [16]. But also produced incentives distortions of government officials, most local government officials under the promotion incentive mainly focus on those indicators which can be quantified assessed. The local economy has become basically the only indicator of higher levels government to measure the lower level government. Subordinate local governments are more inclined to implement the "only GDP" financial spending guidance. Under the current assessment system, economic growth, taxation, infrastructure have become the most important "baton". In order to get better promotion, in limited tenure, local government officials easier to make decision with "pay attention to infrastructure and disregard public services". So that local governments ignore those public service (like science, education, culture and public health etc.) expenditure without obvious effects to economic growth in the short term in economic growth [17], thus lead to inadequate public service spending, especially public cultural spending.

From the perspective of government officials, compare with education and public health, indicators of cultural assessment show more ambiguous and less urgent. As in poor areas, public cultural spending in affluent areas is likewise ignored, the proportion of cultural expenditure to government fiscal expenditure is the smallest in respective the proportion of expenditure in science, education, culture and public health to the government fiscal expenditure. When the total amount of fiscal revenue was unchanged, there is a government spending shift between public cultural services and the local investment environment, education providing, public health, other public services. For example, spending on improvements of investment environment may squeeze out financial expenditure on public cultural services. Promotion competition have promoted economic growth, but also hampered the improvement of local public cultural service level. In order to attract financial capital, the local government officials start tax competition with lower tax rates, tax relief, tax incentives and subsidies, lead to fiscal revenue decline of those local governments. When the public cultural expenditure accounted for government spending is unchanged, public cultural spending is reduced with the revenue decline. Therefore, the performance competition for promotion affects the local government cultural expenditure. We will test it through the following hypothesis:

Hypothesis (H4): Local government officials' promotion competition is negatively associated with public cultural expenditure.

\section{Empirical Tests}

\subsection{Selection and Processing of Variable}

An empirical panel data model is constructed in this section which analyzes the influence of fiscal decentralization on public cultural services in China. Furthermore, empirical results verify the conclusions of theoretical logic in Section 2. In order to analyze better the effects of fiscal decentralization on public cul- 
tural services, we also choose other control variables.

(1) Local Government Expenditure on Public Culture (EC):

This is the explained variable in this empirical study, the proportion of annual budgetary in provincial public cultural expenditure and budgetary in provincial public expenditure is used as the index of public cultural expenditure of local government, which can fairly measure the fiscal expenditure level of provincial governments on public culture services. The proportion of extra-budgetary expenditure in public cultural expenditure of provincial governments is small, and extra-budgetary expenditure is mainly used for investment of infrastructure and other similar public goods [18]. Hence, the index can well describe the provincial fiscal expenditure level on public culture services.

(2) The Index of Fiscal Decentralization (FD)

The core explanatory variable in this empirical study is the index of fiscal decentralization. The greater the degree of fiscal decentralization, the bigger the fiscal expenditure autonomous right, the local government have to adjust the fiscal expenditure structure of the same level in accordance with their preferences, thus affecting the level of public cultural expenditure. The frequentlyused index of decentralization expenditure, i.e., ratio of budgetary fiscal expenditure per capita of provinces to that of central government, was selected as degree of fiscal decentralization, so as to take control of the possible positive relationship between governmental expenditure scale and population size, as well as to carry out per capita management on the decentralization index.

(3) The Degree of Public Financial Self-sufficiency (PFS)

Generally, the government's expenditure structure will be affected by its own balance of financial revenue and expenditure. The degree of public financial self-sufficiency is a measure of the degree of financial autonomy and sufficiency of local government. The better the financial situation of local government, the more likely greater investment into public culture needs, in this way, the public cultural needs of residents can be met. In fact, from aspects of revenue and expenditure autonomous right, fiscal decentralization motivates local government to better serve local residents and increase expenditure in public cultural services [19]. In this paper, the ratio of budgetary revenue to budgetary expenditure of local government is taken as the proxy variable of fiscal autonomy. This variable is expected to exert a positive effect on public cultural expenditure.

(4) Transfer Payment (TR)

The gap between budgetary expenditure and budgetary revenue of the local government is often compensated by the central government's transfer payment to the local government and the local government bond issuance. In general, transfer payment has a property of balancing local fiscal inequity, less developed areas mainly rely on transfer payment to maintain the supply of public goods, and descended transfer payment is likely to improve the government's supply of public goods in these areas. Duncombe and Yinger [20] proposed the "flypaper effect”, namely, every $\$ 1$ increase of local residents' disposable income will only cause $\$ 0.1$ increase in government public expenditure, but \$1 of transfer pay- 
ment from the exchequer of the central government will cause $\$ 0.33$ increase in government expenditure. Relative to the equal tax cutback of the central government, transfer payment can remarkably increase local governments fiscal expenditure on public goods. But on the other hand, according to the above analysis, the defects in domestic transfer payment structure will reduce the proportion of public cultural expenditure. Therefore, we cannot predict the variable symbol.

(5) The Index of Government Competition (FDI)

In literatures, the selecting methods of index of government competition extent differ a lot. The representative ones are as follows: in one case, the absolute value of FDI actually utilized by local government is directly taken as the proxy variable [21], but the value is greatly affected by a country's economic environment and other external factors, lower FDI value cannot explain that the national competitiveness of a province decreased somewhat; in another case, the relative tax rate of foreign-funded enterprise in various regions is taken as the proxy variable [17], but in reality, the data of relative tax rate can only be obtained through complicated conversion method, besides, export rebates, extension of preferential period of tax reliefs and other factors posing great influence on the relative tax rate should be taken into account, making the conversion even more complicated.

In the analysis of theoretical framework in section 2, incentives of local government will exert influence on public cultural expenditure from two aspects, namely, decline in fiscal revenue of local government induced by tax competition and distortion of public expenditure structure caused by investment in infrastructure construction. Hence, government incentive is an important factor affecting public cultural expenditure. To competitively attract foreign direct investment is an important way for local government to carry out yardstick competition, as compared with investment in culture, education and hygiene, investment in infrastructure is capable of achieving a result in a short time. Therefore, to attract FDI in a faster way, the local government will strive to improve infrastructure, thus resulting in distortion of the public expenditure structure and affecting the number of public cultural expenditures. In this paper, the method proposed by Jun Zhang using provincial FDI to describe the competition extent of local government is used for reference, however, to eliminate the influence of exchange rate and macroeconomic changes, the absolute value of FDI is abandoned, and ratio of FDI attracted by local government to national FDI is taken as the proxy variable to measure the government competition extent. According to theoretical exposition above, the expected index coefficient is negative.

(6) Per Capita GDP (PGDP)

In explaining the economics of Wagner's law, the financial scientist Adolf Wagner argues that the growth in public spending on education, culture, recreation, health and welfare services is due to the income elasticity of its larger service demand. As per capita real income rises, the demand for services also increases. Therefore, public spending including public cultural and educational 
expenditure is growing faster than GDP. In order to control the factors of population change, the indicators of economic growth are measured by the per capita GDP of local people. The coefficient is expected to be positive.

(7) Government Burden (GB)

Under normal conditions, larger government scale appears as more government's administrative staff and more bloated structure, besides, the government fiscal expenditure will be occupied by more administrative fees, and the ratio of public cultural expenditure to total expenditure will be reduced accordingly. In this paper, the number of civil servants relative to fiscal revenue of ten thousand yuan is taken as the proxy variable of the index.

(8) Urbanization Rate (UR)

The construction of cultural infrastructure in cities is more perfect than in rural areas. All kinds of public libraries and cultural facilitating agencies are in large quantity and of high standard. Similarly, the standard of public cultural service charge is higher than in rural areas, the central government spends more on urban public culture; in addition, with the progressing of urbanization and concentrating of population, the scale economies effect of public culture service begins to be prominent and cultural expenditure will be saved, therefore, the influence of urbanization process on public cultural expenditure is still unclear. Due to the change of national statistical caliber and the availability of data, this paper uses the ratio of nonagricultural population to total population in the provinces as the proxy variable of urbanization rate.

In consideration of the scale economies effect or crowding effect occurred in public cultural expenditure with population increase, number of population and population density are introduced into the model for control.

\subsection{Model and Data}

Considering all the above factors, we can build the following panel data model

$$
\mathrm{EC}=\alpha_{i t}+\beta \mathrm{FD}+\delta \mathrm{FDI}+\mu \mathrm{FD} \times \mathrm{FDI}+\eta \mathrm{PFS}+\gamma \mathrm{TR}+\lambda \mathrm{PGDP}+\omega \mathrm{CON}+\varepsilon_{i t}
$$

" $i$ " and " $t$ " represent the $i$-th province and $t$-year, respectively. $\varepsilon$ is the residual term.

$\beta, \delta, \mu, \eta, \gamma, \lambda, \omega$ represent different coefficients or coefficient matrix of each variable.

EC, explained variables, is the local government public cultural expenditure. The explanatory variables of interest in this empirical study include fiscal decentralization (FD), public fiscal self-sufficiency rate (PFS), central to local per capita transfer payments (TR), government competition (FDI), per capita GDP (PGDP). CON, group control variable, includes the remaining variable government burden, urbanization rate, population and population density. Since the influence of decentralization on expenditure structure may vary with the degree of competition. According to Fu Yong and Zhang Yan [17], Zheng [22], the interactive item of decentralization and competition degree-FD $\times$ FDI is introduced. 
Based on the availability of data, the provincial panel data for the period 1997-2015 were used for 30 provinces, autonomous regions and municipalities in China ${ }^{1}$. In this empirical analysis, the Tibet area was excluded because the central government gave Tibet a large amount of transfer payments and preferential policies each year, and some data were not available for public cultural expenditure. Relevant data is mainly derived from the annual yearbook, including "China Statistical Yearbook", "China Financial Statistics Yearbook", "China’s Cultural Relics Statistical Yearbook", "Local Statistical Yearbook" and "Statistical Data Compilation of New China for 50 Years".

\subsection{Findings}

To better display the measurement results, five models were constructed based on the above basic model. Model 1 is mainly to study the basic relationship between public culture expenditure and core explanatory variables and control variables. Model 2 is to verify the relationship between government competition and fiscal decentralization to the proportion of public cultural expenditure. This model focuses on three explanatory variables: per capita GDP, fiscal decentralization, and government competition. Model 3 further introduces other control variables on the basis of model 2, such as government per capita transfer payments, government burden and other control variables. Also it continues to test the effects of fiscal decentralization and government competition on the proportion of public cultural spending. In view of the negative effect of fiscal decentralization on the proportion of public cultural expenditure, the interaction term of decentralization degree and competition degree are introduced in Model 4. Model 5 introduces other control variables on the basis of model 4 and continues to test the effect of the decentralized and competitive interaction terms.

As shown in Table 1, the empirical results are as follows:

(1) The degree of fiscal decentralization significantly reduces the proportion of public cultural expenditure, which is consistent in all regressions. The indexes of fiscal decentralization are basically significant when significance level is below 0.01 . All other things being equal, the higher the degree of decentralization, the lower the proportion of public cultural expenditure.

(2) In Model 1, GDP per capita exerts negative effect on the proportion of public cultural expenditure, and the significance level is $1 \%$ likewise. However, in other models, GDP per capita exerts a significant positive effect on the proportion of public cultural expenditure after government competition extent and transfer payment have been controlled. Netzer [23] found that GDP (revenue) or at least revenue related variable, such as the high receipts tax generated with high public expenditure, is weakly positively correlated with public cultural expenditure. The reason why the finding of $\mathrm{H}$ is different from results of other researchers may be as follows: firstly, with the development of China's economy, the cultural expenditure completely taken charge of by the government is gradu-

${ }^{1}$ There are 23 provinces, 4 municipalities, 5 autonomous regions in China. In this paper, we used the data from 23 provinces, 4 municipalities, 4 autonomous regions except Tibet due to a large amount of transfer payments from levels governments. 
Table 1. Regression result: fiscal decentralization, governmental behavior and public cultural expenditure.

\begin{tabular}{|c|c|c|c|c|c|}
\hline & \multicolumn{5}{|c|}{ Public Cultural Expenditure (EC) } \\
\hline & Model 1 & Model 2 & Model 3 & Model 4 & Model 5 \\
\hline $\begin{array}{l}\text { Degree of Fiscal } \\
\text { Decentralization }\end{array}$ & $\begin{array}{c}-1.0172^{* * *} \\
(0.1348)\end{array}$ & $\begin{array}{l}-0.8283^{* * *} \\
(0.1085)\end{array}$ & $\begin{array}{l}-1.3765^{* * *} \\
(0.1522)\end{array}$ & $\begin{array}{l}-0.6989^{* * *} \\
(0.1735)\end{array}$ & $\begin{array}{c}-1.7231^{* * *} \\
(0.1993)\end{array}$ \\
\hline Capita GDP & $\begin{array}{l}0.0066^{* * *} \\
(0.0003)\end{array}$ & $\begin{array}{l}-0.0033^{* * *} \\
(0.0007)\end{array}$ & $\begin{array}{l}-0.0036^{* * *} \\
(0.0006)\end{array}$ & $\begin{array}{l}-0.0034^{* * *} \\
(0.0006)\end{array}$ & $\begin{array}{c}-0.0028^{* * *} \\
(0.0005)\end{array}$ \\
\hline $\begin{array}{l}\text { Government } \\
\text { Competition }\end{array}$ & & $\begin{array}{c}-0.1681^{* * *} \\
(0.0291)\end{array}$ & $\begin{array}{c}-0.0837^{* *} \\
(0.0154)\end{array}$ & $\begin{array}{c}-0.1085^{\star * *} \\
(0.0877)\end{array}$ & $\begin{array}{c}-0.1583^{* *} \\
(0.1209)\end{array}$ \\
\hline $\begin{array}{c}\text { Decentralization } \times \\
\text { Competition }\end{array}$ & & & & $\begin{array}{l}-1.7232^{* *} \\
(0.7081)\end{array}$ & $\begin{array}{l}-0.8978^{*} \\
(0.2767)\end{array}$ \\
\hline Transfer Payment & & & $\begin{array}{l}-1.6451^{* * *} \\
(0.8571)\end{array}$ & $\begin{array}{l}-1.9581^{* * *} \\
(1.2755)\end{array}$ & $\begin{array}{c}-1.0549^{* * *} \\
(0.3958)\end{array}$ \\
\hline $\begin{array}{l}\text { Degree of Fiscal } \\
\text { Self-financing }\end{array}$ & $\begin{array}{l}0.0826^{* * *} \\
(0.0108)\end{array}$ & & $\begin{array}{l}0.0667^{* *} \\
(0.0195)\end{array}$ & & $\begin{array}{l}0.0684^{* *} \\
(0.0422)\end{array}$ \\
\hline Financial Burden & & & $\begin{array}{c}-1.0119^{* * *} \\
(0.6657)\end{array}$ & & $\begin{array}{l}-2.0553 \\
(1.3377)\end{array}$ \\
\hline Urbanization Rate & $\begin{array}{c}-0.0587^{* * *} \\
(0.0015)\end{array}$ & & $\begin{array}{c}-0.0322^{* * *} \\
(0.0107)\end{array}$ & & $\begin{array}{c}-0.0778^{* * *} \\
(0.0202)\end{array}$ \\
\hline Population Density & $\begin{array}{l}0.0287^{* * *} \\
(0.0094)\end{array}$ & & $\begin{array}{c}0.0307 \\
(0.0322)\end{array}$ & & $\begin{array}{c}0.0318 \\
(0.0421)\end{array}$ \\
\hline Population Quantity & $\begin{array}{l}0.0104^{* * *} \\
(0.0021)\end{array}$ & & $\begin{array}{c}0.0029 \\
(0.0006)\end{array}$ & & $\begin{array}{c}0.0038 \\
(0.0068)\end{array}$ \\
\hline$F$-value & 28.34 & 24.37 & 16.81 & 28.97 & 18.73 \\
\hline$P>F / c h^{2}$ & 0.0000 & 0.0000 & 0.0000 & 0.0000 & 0.0000 \\
\hline$R^{2}$-within & 0.4012 & 0.2907 & 0.4941 & 0.3033 & 0.4557 \\
\hline obs & 270 & 270 & 270 & 270 & 270 \\
\hline
\end{tabular}

$* * *, * *,{ }^{*}$ indicate significance levels of $1 \%, 5 \%$, and $10 \%$, respectively; the results of constant terms are omitted.

ally transferring to the residents, not a few of the original cultural undertakings sectors have been pushed to the market, and the proportion of private cultural expenditure is on the increase. Secondly, compared with public expenditures in education, hygiene, scientific research, etc., cultural services have lower revenue flexibility.

(3) Public financial self-sufficiency has a significant positive effect on the proportion of public cultural expenditure, which means that when proportion structure of fiscal expenditure had no great change, the greater the fiscal autonomy of local government, the more the expenditures in culture, hygiene and education. However, a large portion of the local government fiscal expenditure in China comes from extra-budget expenditure and soft constraint exists in the local government budget. In order to develop the economy, local governments competitively invest in infrastructure but ignore soft public goods. Only when the local governments are faced with hard budget constraints, will careful arrangements be made for various public expenditures. 
(4) The coefficient of transfer payment is significantly negative, which verifies the hypothesis in the previous analysis, namely, the current transfer payment in China cannot increase the proportion of public cultural expenditure. As the largest part of transfer payment, public cultural special transfer payment has nonstandard appropriation and usage procedures. Special transfer payment has few expenditure items, and in fact a lot of departments have participated in the allocation of special funds. The departments compete for the special appropriate funds, resulting in that a lot of public cultural special appropriate funds have been retained, occupied and embezzled layer upon layer, but never used in designated ways. In local governments with financial resources shortage, some of the special appropriate funds even become basic spending of the governments and are mainly used for expenditure of civil servants. Tax returns constitute the second major part of transfer payment, the essence of which is the product of maintenance of vested interest. Tax returns cannot equalize financial resources, richer areas will get more tax returns, so for local governments in less developed areas lack of financial resources, and the possibility of increasing proportion of public cultural expenditure by tax returns is small. In addition, general transfer payments without additional conditions obtained by local governments are less likely to be used in public cultural expenditure.

(5) The coefficient of government competition extent is also significantly negative. Models 2 and 4 are significant at 1\% level, while Models 3 and 5 are significant at $5 \%$ level, indicating that per one percentage point increase of government competition extent will cause at least 0.08 percentage points decrease in the proportion of public cultural expenditure. This preliminarily verifies the previous hypothesis, i.e., competition for growth among local governments will distort the structure of public expenditure and reduce public cultural expenditure. Furthermore, the interaction term of decentralization degree and competition extent has been introduced into Models 4 and 5. The regression results show different significance levels. The significance level is higher in Model 4, but the coefficients are all negative, indicating that in addition to the direct impact on the proportion of public cultural expenditure, decentralization also exerts an indirect negative impact on the proportion, which depends on the competition extent. In Model 4, fiscal decentralization directly leads to a decline in the proportion of public cultural expenditure, and every 1 percentage point increase of decentralization will cause 0.69 percentage points decrease in the proportion of public cultural expenditure. The coefficient of interaction term of fiscal decentralization and government competition extent is significantly negative. The fiercer the competition, the greater the negative impact of decentralization on public cultural expenditure. Each 1 percentage point increase of the interaction degree between government competition extent and decentralization will lead to 1.72 percentage points decrease in public cultural expenditure.

(6) Results of other control variables: the coefficient of government burden is significantly negative, which is consistent with the null hypothesis but merely significant in Model 3. This indicates that the larger the government scale and 
the heavier the burden, the more public resources the government will consume and the less expenditure in public cultural services. Urbanization rate has a significant negative effect on public cultural expenditure, for which the reason may be that with the processing of urbanization, the cost saving brought by scale economy of public cultural services is larger than the increase of expenditure caused by high standards of urban public cultural services. The urbanization of public cultural services can reduce the burden of local finance. The coefficient of population density is significantly positive in Model 1 and the reason may be that with increasing population density, higher congestion cost and maintenance cost have exceeded the cost saving brought by scale economy. The symbol of population variable is merely significantly positive in Model 1 , the reason for which is as follows: as public goods, public cultural services have congestion in this area, as a result, the marginal cost of one more consumer of public cultural services is larger than zero, although the fixed cost of public cultural services will decrease with the increased number of consumption, the effect of added marginal cost is more significant.

\subsection{Robustness Test}

Here, we will carry out robustness test on the main explanatory variables in the model. As the social, economic and natural conditions in direct-controlled municipalities are significantly different from those in provinces and autonomous regions, municipalities have been excluded in this study, and regression is only carried out on observed values of other provinces and autonomous regions; Model 1 presents the regression on other provinces and autonomous regions when observed values of 4 municipalities are excluded. In addition, the observed values of fiscal decentralization degree, government competition extent and per capita GDP deviate from the mean value and are mainly distributed on the right side, for these three variables, the observed values that are 1.5 standard deviations greater than the mean value are excluded. Model 2 presents the regression that removes the observed values of decentralization degree which are 1.5 standard deviations greater than the mean value; Model 3 presents the regression that removes the observed values of competition extent which are 1.5 standard deviations greater than the mean value; Model 4 presents the regression that removes the observed values of per capita GDP which are 1.5 standard deviations greater than the mean value. The fiscal decentralization degree, the government competition extent, the interaction term of decentralization and competition as well as the per capita GDP are significantly negative in the subdivided subsample regression. Therefore, it can be evaluated that the above variables have favorable robustness (Table 2).

\section{Conclusions and Policy Recommendations}

\subsection{Conclusions}

This article carries out the analysis on vertical structural imbalance of public cultural expenditures between local governments and the central government; the 
Table 2. Robustness testing result.

\begin{tabular}{ccccc}
\hline & \multicolumn{3}{c}{ Public Cultural Expenditure (EC) } \\
\cline { 2 - 5 } & Model 1 & Model 2 & Model 3 & Model 4 \\
\hline Degree of Fiscal & $-0.6011^{* * *}$ & $-0.9983^{* * *}$ & $-1.2115^{* * *}$ & $-1.6226^{* * *}$ \\
Decentralization & $(0.1073)$ & $(0.1636)$ & $(0.1633)$ & $(0.1677)$ \\
Capita GDP & $-0.0031^{* * *}$ & $-0.0027^{* * *}$ & $-0.0032^{* * *}$ & $-0.0026^{* * *}$ \\
Government & $(0.0008)$ & $(0.0007)$ & $(0.0005)$ & $(0.0006)$ \\
Competition & $-0.1707^{* * *}$ & $-0.2854^{* *}$ & $-0.2202^{* * *}$ & $-0.1412^{* *}$ \\
Decentralization $\times$ & $(0.1252)$ & $(0.1676)$ & $(0.1322)$ & $(0.1004)$ \\
Competition & $-3.5371^{* *}$ & $-4.7757^{* *}$ & $-6.3968^{* *}$ & $-1.3573^{*}$ \\
$F$-value & $(1.7075)$ & $(1.0009)$ & $(2.5027)$ & $(1.6629)$ \\
$P>F /$ chi & 32.52 & 12.71 & 27.42 & 29.69 \\
$R^{2}$-within & 0.0000 & 0.0000 & 0.0000 & 0.0000 \\
obs & 0.3863 & 0.1044 & 0.1546 & 0.4116 \\
& 242 & 252 & 259 & 263 \\
\hline
\end{tabular}

${ }_{* * *}^{*}, * *,{ }^{*}$ represent the significance level of $1 \%, 5 \%$ and $10 \%$ respectively; the standard error of heteroscedasticity (Robust Std. Err.) is enclosed in brackets; the result of the constant term is omitted.

public cultural expenditure of local government accounts for the majority of the share of public cultural expenditure, while the central government is just in charge of a small part of the expenditure, hence, in such a vertical structure, public cultural expenditure of local government is quite important for the supply of public cultural services. However, in local governments, the proportion of public cultural expenditure in fiscal expenditure has been in decline for years, resulting in a decrease in the proportion of national public cultural expenditure. Hence, the central and local structures of public cultural expenditure need to be optimized. Based on certain theoretical framework, this chapter uses data which was from 1997 to 2015 to investigate the reasons for the decline in the proportion of local government's public cultural expenditure.

The financial power and routine power of China's public cultural expenditure are not well matched. The central and provincial governments with abundant financial resources bear less responsibility in public cultural expenditure, while county-level and township-level governments with less financial resources bear most of the public cultural expenditure. The adverse impact of such fiscal decentralization system leads to China's insufficient public cultural expenditure. Fiscal decentralization degree, government competition extent and GDP per capita all exert a significant negative effect on public cultural expenditure, and a basically consistent conclusion was obtained in the robustness test which removed all samples with abnormal observed values. Transfer payment can increase the gross of public cultural expenditure of local governments, however, a large part of the transfer payment funds has been occupied and diverted to other items of expenditure; the positive impact of transfer payment on public cultural expenditure is no greater than that of government fiscal revenue, and the proportion of public cultural expenditure declined, for which the main reasons are as follows: the current transfer payment system in China has some defects, the 
management of special transfer payment is not perfect, the ratio of tax returns that cannot play the role of equalization is slightly higher, but general transfer payment that actually exerts the effect of equalization is insufficient. Considering other influencing factors comprehensively, the empirical results also suggest that financial burden and urbanization rate have a significant negative effect on China's public cultural expenditure, while fiscal autonomy, population density and number of population have a significant positive effect on our country's public cultural expenditure.

\subsection{Policy Recommendations}

(1) According to the requirements of sound financial system with matched financial resources and routine power, the central and local cultural powers and expenditure responsibilities should be reasonably defined, and the central government should increase the ratio of public cultural expenditure.

The distribution of central and local expenditure responsibilities has always been a hot topic in the research of fiscal science. An American scholar proposed the "decentralization of authority according to benefit principle", and he believed that, the functions of governments at all levels should be effectively distributed based on the beneficial scope of public goods, which can be used as a basis to allocate the financial power. Therefore, those public goods beneficial to all the citizens should be provided by the central government. Besides, although some public goods only benefit a certain social bracket or certain people, they are vital for the development of the whole society and the country, hence, the central government should also provide them. Public culture has the feature of a wide range of publicity and public welfare, and positive values and sense of culture admitting are essential to the development of the society and the country, so public culture should be provided by the central government. Hence, in matters involving the general interests of the country and people, such as safeguarding national cultural security, promoting "Going-Out" of Chinese culture and strengthening cultural heritage protection, the central finance should assume the primary liability of investment. The system of public cultural services is an important carrier to meet the masses' basic cultural rights and interests, its construction should give full play to the macro-regulation function of the central government, and the central government should play a leading role in rationally confirming the respective ratio of share of input of central and local finances. The local finance should assume the main input responsibility for the development of local characteristic culture, and the central finance should provide major support to local finances with great input intensity and obvious working results by means of substituting subsidies with rewards. The responsibility distribution of financial cultural investment at lower-provincial level should be regulated, and the cultural expenditure responsibility of provincial governments should be strengthened [24].

(2) Reform of the performance appraisal system for government officials.

It is proved in this part that the incentive mechanism and yardstick competi- 
tion for officials in local government have significantly distorted the behaviors of the local government. The official promotion system with GDP as the assessment criterion makes local government officials focus on immediate interests and ignore the public cultural expenditure that cannot directly enter into the production function during the tenure of officials, thus restraining the public cultural expenditure. The biggest problem in promotion incentives between officials is the lack of preference revelation of residents in the prefecture, and at the early stage of economic development and market transformation, such preference substitution had certain rationality: at the preliminary stage of economic development, income increase was the maximum demand of the great majority of people, however, the higher the income and the more improved the living conditions, the more diversified people's preferences and demands, at this time, the GDP growth index cannot accurately represent the diversified preference structure of regional residents, but if these diversified preferences can be successfully turned into the content of public services of the government and implemented to meet needs of the people, then people's general welfare will be improved. However, residents and enterprises directly bearing the local governance consequences cannot directly affect the promotion of local officials in the political market, only superior government possesses the power of appointment and removal, hence, the current official appointment mechanism cannot guarantee that local officials can respond adequately and effectively to diversified preferences of the residents and enterprises. Therefore, introducing public satisfaction in the prefecture into work performance of local officials in a proper way and making it become a key factor affecting official promotion is an effective path to promote structure optimization of the government expenditure [25].

(3) The special transfer payment system for public cultural expenditure should be improved and the proportion of general transfer payments should be increased. In consideration of characteristics of the special transfer payment system, namely, overflowing, bustiness, particularity and non-stationarity, the standards should be clearly defined, the access conditions and size be controlled, the administrative supervision be strengthened and the service efficiency of special transfer payment funds be improved. Due to the inherent defects of tax returns, public cultural expenditure should be systematically included into general transfer payment with the effect of equalization, which is conducive to further promoting the equalization of public cultural services on one hand, and promotes the local government to increase public cultural expenditure on the other hand.

\section{Research Prospects}

The ways on government cultural expenditure is also an important factor affecting the efficiency of delivery on public cultural service. Project expenditure on pubic cultural services from level governments or intergovernmental transfers is a very important fiscal spending way. However, there is not enough research on the project expenditure of public cultural services in this paper. We will focus 
the further research on the problems in the implementation of project system of public cultural service which have a great influence on the efficiency on the delivery of public cultural service.

\section{Funding}

The paper is supported by National Social Science Fund Project (11CGL099).

\section{References}

[1] Getzner, M. (2002) Determinants of Public Cultural Expenditures: An Exploratory Time Series Analysis for Austria. Journal of Cultural Economics, 26, 287-306. https://doi.org/10.1023/A:1019976717566

[2] Werck, K., Heyndels, B. and Geys, B. (2008) The Impact of "Central Places" on Spatial Spending Patterns: Evidence from Flemish Local Government Cultural Expenditures. Journal of Cultural Economics, 32, 35. https://doi.org/10.1007/s10824-007-9056-5

[3] Benito, B., Bastida, F. and Vicente, C. (2013) Municipal Elections and Cultural Expenditure. Journal of Cultural Economics, 37, 3-32. https://doi.org/10.1007/s10824-012-9175-5

[4] Chen, W. (2006) Public Cultural Service System Research. Shenzhen Press Group Press, Shenzhen.

[5] Cao, Z. (2006) The Development of Rural Public Cultural Undertakings Should Be Led by Government. Journal of Northeast University of Finance and Economics, No. 5.

[6] Wang, L., Guo, Q. and Xiao, Q. (2009) National Public Cultural Service System Theory. Culture and Arts Publishing House, Beijing.

[7] Ma, H. and Cheng, L. (2009) Perfecting Fiscal Policy to Promote the Construction of Public Cultural Service System. China Finance, No. 12.

[8] Zhang, J. (2010) To Promote the Development of China's Public Cultural Service System, Fiscal Policy Research. Contemporary Finance and Economics, No. 8.

[9] Wang, G. and Wang, J. (2008) Organization of China's Cultural Expenditure Structure Optimization. East China Economic Management, No. 5.

[10] Mao, S. (2009) Public Cultural Policy Theory and Practice. Haitian Publishing House, Shenzhe.

[11] Jiang, G. (2011) Public Cultural Services Financial Investment Mechanism. China Administration, No. 1.

[12] Luo, M. (2008) Construction of Minority Areas of Public Cultural Services Financial Security Mechanism. Yunnan Social Sciences, No. 6.

[13] Wang, R. (2010) Rural Public Cultural Service System Construction: Financial Responsibility and Funding Guarantee Mechanism. Local Finance Research, No. 8.

[14] Davey, K. (2003) Fiscal Decentralization. World Bank, Washington DC.

[15] Qian, Y. (2002) Understanding Modern Economics. Comparison of Economic and Social Systems, No. 7.

[16] Zhang, J. (2005) China's Economic Development: Competition for Growth. World Economic News, No. 8.

[17] Fu, Y. and Zhang, Y. (2007) Chinese Decentralization and Fiscal Expenditure Structure Bias: The Cost of Competition for Growth. Management of the World, No. 3. 
[18] Ping, X. (2007) China's Local Government Expenditure Scale Expansion Trend. Comparison of Economic and Social System, No. 1.

[19] Jin, H., Qian, Y. and Weingast, B.R. (2005) Regional Decentralization and Fiscal Incentives: Federalism, Chinese Style. Journal of Public Economics, 89, 1719-1742.

[20] Duncombe, W. and Yinger, J. (1993) An Analysis of Returns to Scale in Public Production, with an Application to Fire Protection. Journal of Public Economics, 52, 49-72.

[21] Zhang, J. and Gao, Y. (2007) Official Tenure, Off-Site Communication and Economic Growth-Evidence from Provincial Experience. Economic Research, No. 11.

[22] Zheng, L. (2008) Foreign Decentralization, Government Competition and Public Expenditure Structure. Economic Sciences, No. 1.

[23] Netzer, D. (1992) Differences in Reliance on User Charges by American State and Local Governments. Public Finance Quarterly, 20, 499-511.

https://doi.org/10.1177/109114219202000407

[24] Xie, X. (2011) Innovating Fiscal Policy Mechanism to Promote Cultural Development and Prosperity. Finance Research, No. 12.

[25] Zhou, L., Li, H. and Chen, Y. (2005) Relative Performance Appraisal: An Empirical Study on the Promotion Mechanism of Local Officials in China. Journal of Economics, No. 8.

\section{Submit or recommend next manuscript to SCIRP and we will provide best} service for you:

Accepting pre-submission inquiries through Email, Facebook, LinkedIn, Twitter, etc. A wide selection of journals (inclusive of 9 subjects, more than 200 journals)

Providing 24-hour high-quality service

User-friendly online submission system

Fair and swift peer-review system

Efficient typesetting and proofreading procedure

Display of the result of downloads and visits, as well as the number of cited articles

Maximum dissemination of your research work

Submit your manuscript at: http://papersubmission.scirp.org/

Or contact tel@scirp.org 